\title{
Cold-adapted organic solvent tolerant alkalophilic family I.3 lipase from an Antarctic Pseudomonas
}

\begin{abstract}
Lipolytic enzymes with cold adaptation are gaining increasing interest due to their biotechnological prospective. Previously, a cold adapted family I.3 lipase (AMS8 lipase) was isolated from an Antarctic Pseudomonas. AMS8 lipase was largely expressed in insoluble form. The refolded His-tagged recombinant AMS8 lipase was purified with $23.0 \%$ total recovery and purification factor of 9.7. The purified AMS8 lipase migrated as a single band with a molecular weight approximately $65 \mathrm{kDa}$ via electrophoresis. AMS8 lipase was highly active at $30{ }^{\circ} \mathrm{C}$ at $\mathrm{pH} 10$. The half-life of AMS8 lipase was reported at 4 and $2 \mathrm{~h}$ under the incubation of 30 and $40{ }^{\circ} \mathrm{C}$, respectively. The lipase was stable over a broad range of $\mathrm{pH}$. It showed enhancement effect in its relative activity under the presence of $\mathrm{Li}^{+}, \mathrm{Na}^{+}, \mathrm{K}^{+}, \mathrm{Rb}^{+}$and $\mathrm{Cs}^{+}$after 30 min treatment. Heavy metal ions such as $\mathrm{Cu}^{2+}, \mathrm{Fe}^{3+}$ and $\mathrm{Zn}^{2+}$ inhibited AMS8 activity. This cold adapted alkalophilic AMS lipase was also active in various organic solvent of different polarity. These unique properties of this biological macromolecule will provide considerable potential for many biotechnological applications and organic synthesis at low temperature.
\end{abstract}

Keyword: Family I.3 lipase; AMS8 lipase; Solvent tolerant; Cold-adapted; Pseudomonas sp.; Inclusion bodies; Alkaline lipase 